\title{
A New Approach of Preventing Backdraft Explosion in Commercial Buildings by Implementing Sensor Technology
}

\author{
Md Mehedi Hasan and Md Nur Ali
}

\begin{abstract}
The aim of this design is to provide real time updates to people in the area of the hazard by detecting the danger and alerting persons nearby with audible alarm as well as visual one. This system intended to supplement an existing fire door in a secured building. This design utilizes multiple temperature and gas sensors in various rooms of a large building to detect the presence of a fire or any hazardous gasses, interface system at the entrance to each room alert anyone to potential hazards within and guide them to nearest exit and a central controller device for each floor collects data from the sensor periodically and then displays the status of each room by a web interface and by short message service (SMS) or email alerts by desired.
\end{abstract}

Index Terms-Fire detection, gas sensor, thermistor temperature sensor, back-draft.

\section{INTRODUCTION}

Today the buildings that we live, work and study in have become larger, taller and more enclosed. All the time we are using more advanced technologies and systems that are relied upon for our safety. If a short circuit were to occur due to one of these machines a fire would likely result and in such an enclosed space this would be catastrophic. Every year, hundreds of lives and hundreds of millions of dollars of property are damaged as the result of fire related incidents. If this were to occur somewhere in a highly populated area, such as office building, multi storied residential building the difficulty of rescuing people involved and preventing the damage is even greater. Evacuation is a major issue in high rise buildings that has no efficient or fool proof solution. This issue has proved difficult even for firemen to handle; therefore, a better and more efficient system is needed to help improve safety for human lives and equipment. This design informs people in the area of the system where the fire is, how the fire is progressing at the moment and also provides a best evacuation route. This will save time in an emergency and allow for the evacuation of endangered people as the incident begins.

Manuscript received April 26, 2012; revised June 4, 2012. The authors wish to acknowledge the assistance and support of Professor Glenn Matthews-RMIT University.

Md Mehedi Hasan is with the School of Electrical and Computer Engineering, RMIT University, Melbourne, Australia (e-mail: mehedi.hasan.ivan@gmail.com).

Md Nur Ali is with the School of Electrical and Computer Engineering, RMIT University, Melbourne, Australia.

\section{RESEARCH BACKGROUND}

A Fire Alarm Control Panel (FACP) is a component which takes the role of central controlling in a Fire Alarm System. The panel collects information from sensors to detect changes related to fire, monitors the working status of all components and provides for transfer of necessary information for preparation of a predetermined fire accident. There are two types of panels which are most commonly used in buildings: conventional systems and addressable systems. Conventional systems such as the HCA [1] and FireNET [2] control panel usually have lower initial equipment costs compared with addressable systems. Furthermore, many also have wider ranges of compatible devices and can be easier to program. However, due to their limited expansion capability, conventional systems are used less frequently in large buildings than in the past. But they are still not uncommon on smaller projects such as small schools, stores, restaurants and apartments.

Larger systems and increasing demand for more detailed diagnostic and location information have led to the introduction of addressable systems with each addressable device providing specific information about its state while sharing a common communication circuit. Addressable systems are much easier to install. Moreover, there are more system status information at the panel and central station of addressable systems. Additionally, input/output programming becomes much more flexible. And consequently, there are much more room available to expand. Yet for all the optimism, there are big questions about whether the application of addressable systems can be afforded considering its startling high price.

Fire Alarm systems are installed as needed on a per building basis. Buildings classified as institutional, schools, hotels, dormitories, and high-rises are required to have fire alarm systems installed. However, smaller buildings (such as small schools, stores, restaurants, and apartments) are still using conventional fire alarm systems because of their low needs of technology and demand of low price. On the other hand, modern high-rises are usually able to afford a huge cost for expensive addressable fire alarm systems as they have a request of high safeness.

Compared with all other similar existing designs[4]-[9] on the market, this design has characteristics of low cost, simple operability, high safeness, central detailed temperature monitoring and has good application prospect. Furthermore, it has some extra unique functions including guiding people the correct direction to run away from a fire accident as well as checking status of every sensor from a website. 


\section{DEVELOPMENT}

Research into some past incidents and consultation with the Melbourne Fire Brigade has found that the main concern in fire related emergencies is Backdraft. Backdraft is the phenomenon that results from an opening door allowing additional air (oxygen) to reach the fire, thus fuelling it and causing an outburst in an emergency, people act in fear and impulsively as are in survival mode. This means that doors can be opened without realising the implications and risk of backdraft. This issue is combated by the design which shows the room health before opening the door. This is an integral hardware system which will be used with the existing fire door. The system will use temperature and gas sensors to detect the presence of fire as well as any hazardous gases. The interface system will be alongside each door has two right and left LEDs green arrows to guide people to the safest evacuation route and one green LED to show the healthy state of the room and will. The red crossed LEDs indicate fire detection inside the room thus preventing people from opening the door to reduce the risk of back-draft. The room health and safety data will also be viewable on a website which can be accessed anywhere within the defined network and display the temperature of each room, whether it's safe or dangerous and if any gasses are detected. The website will also send SMS messages to chosen numbers if the levels become dangerous to allow for faster reactions. This design will provide passive fire protection and back draft prevention by warning people of possible dangers and providing constant health updates.

This system comprises several main sub-systems:

- Interface circuit

- Temperature sensor circuit

- Gas sensor circuit

- Web interface and SMS

\section{A. Block Diagram}

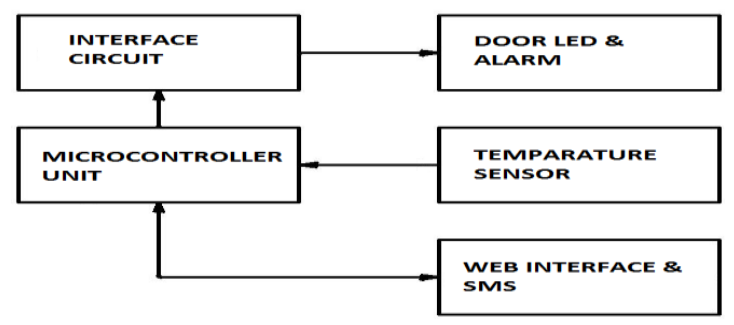

Fig. 1. Block diagram of the system.

The temperature sensors collect the room's temperature and pass it to the micro-controller. Then Micro-controller will analyse all the data and will send vital message to the interface circuit. The interface circuit decodes the message, turning the LED to depict the current room status and closest exit as well an audible warning in the case of fire. Micro-controller will simultaneously send the collective information to the subscribed member through a secured website and SMS.

\section{B. Interface Circuit}

Interface circuit decodes the indication coming from micro-controller unit.To minimise the wires running from MCU to the interface board authors used twin inputs from the microcontroller to drive the 4 states of the interface board.
The states are as follows:
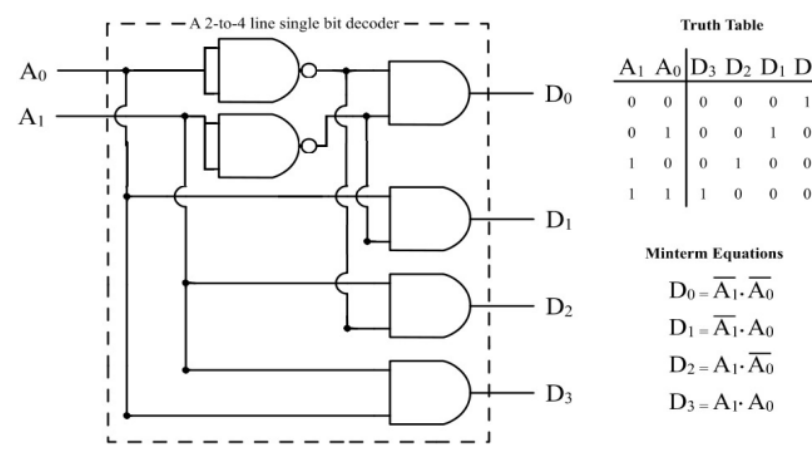

Fig. 2. Boolean logic of interface circuit.

TABLEI: INTERFACE CIRCUIT STATES

\begin{tabular}{|c|l|}
\hline D $_{\mathbf{0}}$ (State 0) & Healthy state LED \\
\hline $\mathbf{D}_{\mathbf{1}}$ (State 1) & Left green LED arrow \\
\hline $\mathbf{D}_{\mathbf{2}}$ (State 2) & Right greed LED arrow \\
\hline $\mathbf{D}_{\mathbf{3}}$ (State 3) & Red LED cross with buzzer \\
\hline
\end{tabular}

\section{Oxygen and Gas Sensor}

The gas sensor, MQ-2 contains an element within it which has a characteristic that changes its resistance depending on the quantity of flammable substances and smoke in the vicinity of the sensor. The greater the concentration of substances within the scope of the sensor, the lower the resistance of the element in the sensor therefore the voltage drop across the load resistor will increase with the detection of substances. Another characteristic of the element in the sensor is that the resistance at low temperatures can be equivalent to when hazardous substances are affecting the sensor. Therefore the sensor needs to be preheated before accurate operation can be achieved. Through testing the required preheat time was found to be 5 minutes until the sensor reported sufficiently accurate ambient levels while maximum sensitivity may take up to 30 minutes to achieve. Before this time the sensor may report warning and alert levels lower than what they should be.

To implement this into the microprocessor the thermistor is used in series with a $4.7 \mathrm{kOhm}$ resistor to create a voltage divider circuit. When the temperature increases the resistance exponentially decreases therefore causing the voltage drop across the resistor to increase.

\section{- Analysis 1}

The gas sensor is able to detect Flammable gasses at between 300 and 10,000 ppm (parts per million). It will be suitable for this design as it does not need to be terribly accurate, so long as it can confirm the presence of a dangerous gas.

Since the aim of the design is to detect any flammable substances as quickly as possible; the most sensitive load resistance should be chosen. The resistance of gas sensor decreases with the presence of flammable substances therefore the lowest load resistance available will give the most sensitivity as shown in table II. Since there was no need to accurately measure the amount of substances in the area of 
the sensor but rather just detect the presence of any it is best to use the lowest resistance of $5.1 \mathrm{kOhms}$ which still gave nearly full use of the output levels available. A spray of butane at $5.1 \mathrm{kOhm}$ load produced $4.7 \mathrm{~V}$ compared to $4.95 \mathrm{~V}$ at a load of $40.8 \mathrm{kOhm}$. Therefore there is little loss in usable range of outputs and an output of $4.7 \mathrm{~V}$ at a load resistance of $5.1 \mathrm{kOhm}$ would mean that there is a significant amount of flammable gasses in the air.

It is shown that the compressed air had a significant impact on the readings output from the sensor. This is most likely due to the fact that the element in the sensor is inaccurate at low temperatures (hence the preheat time requirement) and the compressed air would have worked to cool this element thereby giving a false positive reading. Therefore if the gas sensor is to be implemented it should be enclosed so that gasses in the air can enter the sensor but strong cooling winds, possibly from a window or air conditioning system, cannot affect the results from the sensor.

TABLE II: Results of SubSTANCE EFFeCt On LOAD Voltage DroP.

\begin{tabular}{|l|c|c|c|}
\hline Substance & \multicolumn{3}{|c|}{ Voltage Output (Vrl) } \\
\hline Load Resistance (RL) & $5.1 \mathrm{kOhm}$ & $20.4 \mathrm{kOhm}$ & $40.8 \mathrm{kOhm}$ \\
\hline None & 0.81 & 2.2 & 3.2 \\
\hline Blowing air & 0.92 & 2.4 & 3.5 \\
\hline $\begin{array}{l}\text { Compressed air spray } \\
(15 \mathrm{~cm})\end{array}$ & 4.3 & 4.8 & 4.96 \\
\hline & & & \\
\hline Butane (1 second burst) & 4.7 & 4.5 & 4.95 \\
\hline $\begin{array}{l}\text { Light smouldering } \\
\text { smoke }\end{array}$ & 2.8 & 4.0 & 4.2 \\
\hline Medium Smoke & 3.3 & 4.5 & 4.6 \\
\hline Isopropyl alcohol & 3.6 & 4.2 & 4.8 \\
\hline
\end{tabular}

At $5.1 \mathrm{kOhms}$ load resistance the voltage output for smoke detection was between $2.8 \mathrm{~V}$ and $3.3 \mathrm{~V}$ while flammable substances were between $3.6 \mathrm{~V}$ and $4.7 \mathrm{~V}$. Ambient output levels are below $1 \mathrm{~V}$ but an appropriate warning level would be any output above $1.5 \mathrm{~V}$ as to avoid false warnings caused by cooling of the sensor. An appropriate alert level would be any output above $3 \mathrm{~V}$ although it is important to note that large amounts of cooling will raise the output to $4 \mathrm{~V}$ and cause a false positive.

If higher accuracy was required, up to $24 \mathrm{~V}$ can be applied across the sensor and load resistor to allow a larger range of output voltages. This is not possible for this design as the current design with the Atmega32 does not allow for higher ranges that $0 \mathrm{~V}-5 \mathrm{~V}$ on the analogue to digital input pins, but opt-coupler or other method can be used to reduce the voltage level hence ensuring the safety of the micro-controller.

\section{- Analysis 2}

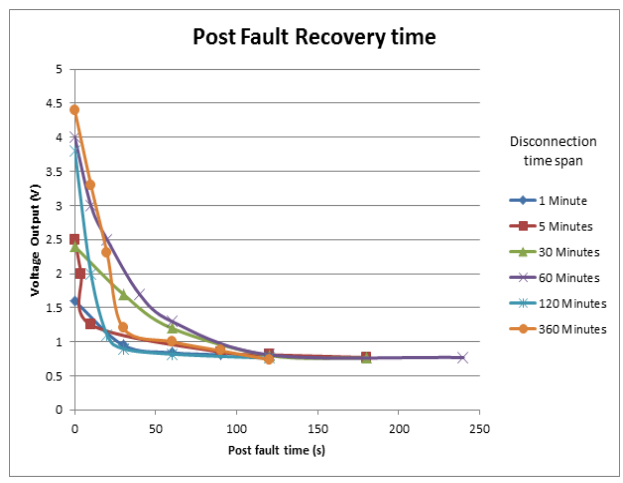

Fig. 3. Graph of results from test 2 .
An acceptable level for the sensor is an ambient output of less than $1 \mathrm{~V}$ therefore from the results obtained the sensor can recover from a short power disruption of one minute within 30 seconds. After a 3 day disconnection from a power source the sensor took 60 seconds to reach a satisfactory level and 2 minutes to reach ambient levels.

\section{- Analysis 3}

While the sensors reached satisfactory level within 2 minutes after a power disruption it appeared to take much longer to reach the same accuracy as before the disruption. It was found that accuracy returned to normal after 20 minutes for disruptions up to 6 hours but disruptions of longer could take up to 30 minutes before the sensor is back to normal.

TABLE III: RESUlTS OF POWER DISRUPTION ON SENSOR ACCURACY.

\begin{tabular}{|l|l|l|l|l|}
\hline \multirow{2}{*}{$\begin{array}{l}\text { Disruption } \\
\text { Time }\end{array}$} & \multicolumn{5}{|c|}{ Post fault time (min) } \\
\cline { 2 - 5 } & 5 & 10 & 20 & 30 \\
\hline No Disruption & 3.6 & 3.6 & 3.6 & 3.6 \\
\hline 5 Minutes & 3.3 & 3.6 & 3.6 & 3.6 \\
\hline 30 Minutes & 3.2 & 3.6 & 3.6 & 3.6 \\
\hline 1 Hour & 2.9 & 3.5 & 3.6 & 3.6 \\
\hline 2 Hours & 2.9 & 3.5 & 3.6 & 3.6 \\
\hline 6 Hours & 3 & 3.4 & 3.6 & 3.6 \\
\hline 1 Day & 3 & 3.3 & 3.4 & 3.6 \\
\hline 3 Days & 3 & 3.2 & 3.3 & 3.6 \\
\hline
\end{tabular}

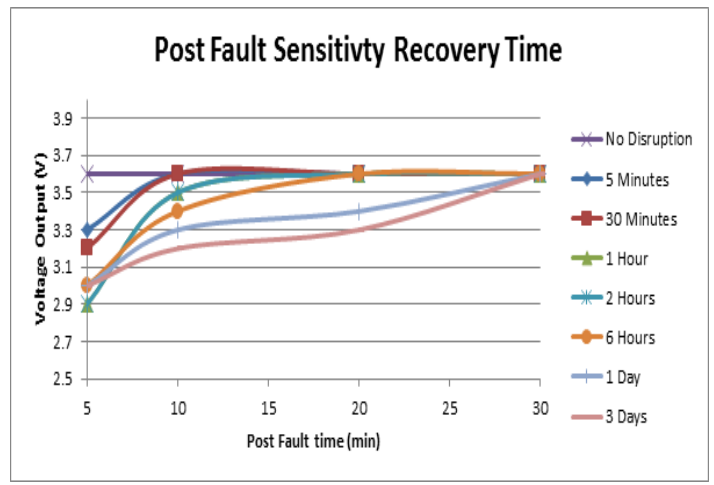

Fig. 4. Graph of results from analysis 3

The sensor is most sensitive with a load resistance of $5 \mathrm{kOhms}$ and at this resistance the ambient voltage drop across the load is below $1 \mathrm{~V}$. Warning alerts should be activated when the voltage rises above $1.5 \mathrm{~V}$ and alerts when above $3 \mathrm{~V}$. To be safe the sensor should be powered for at least 2 minutes before any readings are taken as the sensor may be too cold and output levels would indicate a warning or alert. Although the sensor may not be completely accurate until up to 30 minutes after the sensor has been connected to power but it will still indicate the presence of any substances but the voltage output may not be as high as it should be and therefore a warning or alert may be delayed. In terms of enclosure the sensor should be protected from any cool breezes as much as possible. If the enclosure is to be mounted on the ceiling then the enclosure would be impenetrable from the side but there will be an opening on the bottom to allow substances to enter the sensor.

\section{Temperature Sensor (RN3440)}

Initial plans were to use the DS18B20 temperature sensor which utilised one wire technology to deliver digital temperature readings to the microprocessor. However complications in implementing the sensor and time 
constraints resulted in falling back to the backup option of a RN3440 thermistor. Instead of all of the sensors being connected to a single pin they will be connected as a voltage divider circuit to individual pins with analogue to digital converters. This limits each board to interacting with a maximum of eight temperature or gas sensors which simply means that there would be a board for each level of a building.

The thermistor rated at $10 \mathrm{k} \Omega$ in an ambient room temperature of 25 degrees Celsius that has a greater resistance at lower temperatures and a lower resistance at higher temperatures. As the key temperature range is 35 to 65 degrees Celsius for the project, a smaller range such as $1 \mathrm{k} \Omega$ or $5 \mathrm{k} \Omega$ would not allow for accurate enough results.

From the results it was possible to fit a tread line to map the relationship between the resistance and temperature. This was found to be Temperature $=77.03129 * 0.999866$ Resistance

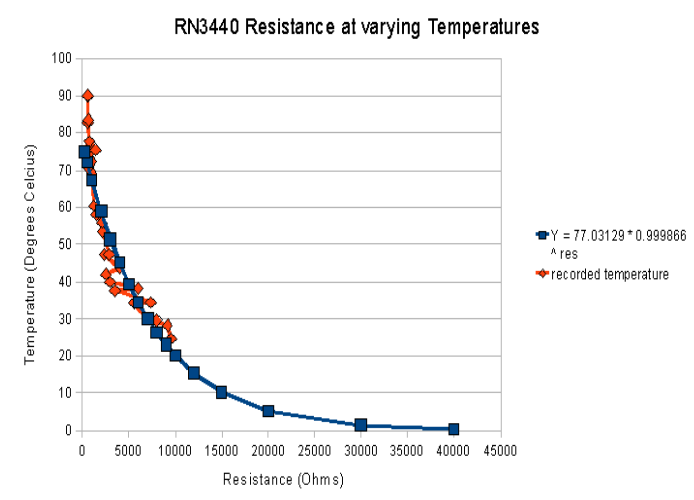

Fig. 5. Graph of recorded temperature vs. resistance and matching best fit equation.

The thermistor requires no warm up time and can be used with any voltage - the selection of a $5 \mathrm{~V}$ source is again for simplicity, as the microprocessor already outputs $5 \mathrm{~V}$. The in series resistor needs to be the same as the rated resistance of the temperature sensor so that calculations can be accurate. The $10 \mathrm{k} \Omega$ thermistor is the correct strength, as the resistance varies greatly with temperature and the temperature can be calculated more accurately, allowing for more accurate testing results and ultimately a correct response in the design in the event of a temperature rise.

\section{E. Web Site and SMS Alerts}

Email alerts generated by the PHP website have proved to be no issue but on the other hand many SMS gateway services were investigated to implement the SMS notifications. Many services had a delay between sending the message and receiving it which was not satisfactory for authors purpose while others were difficult to interface with. SMS has been chosen over email as SMS is more likely to be read at the time, i.e. if the fire marshal is away from their desk they won't respond to the email alert immediately.

\section{RESULTS}

There is a high importance placed on this design being able to notify the required personnel as soon as possible in the event of any risk of fire. This is especially true for when nobody is in the vicinity of a computer displaying the status page which would be most common for smaller businesses which do not have the resources to hire security room personnel. To address this issue it was devised that individuals would be able to be contacted by Email or SMS. SMS alerts will be handled by a SMS Gateway service. By configuring a URL that is sent to the servers. It is possible to send an SMS to a virtually unlimited amount of phone numbers. The email addresses and phone numbers for alerts are able to be configured on the status page.

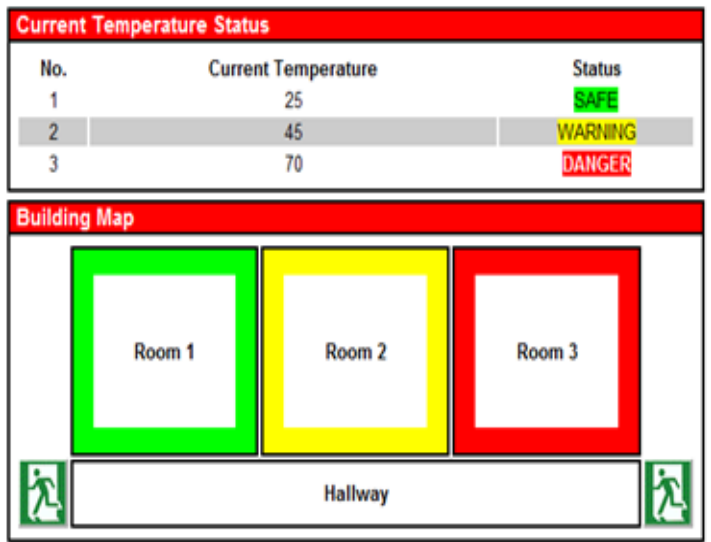

Fig. 6. The status page, run from any computer connected to the Main Board.

The status page displays the current temperature being reported by each of the temperature sensors and what status that temperature corresponds to. Temperatures below 36 degrees Celsius report a healthy green label; temperatures above 65 degrees Celsius report a red alert label and temperatures in-between report a yellow warning label. Along with the temperature readings there is a map of the building with each room coloured according to the status of the room as to allow quick identification of the location of any hazards within the building. Rooms equipped with a sensor will also display a warning or alert display on the map if any flammable substances or smoke is detected. Finally the website provides configuration of the email addresses and phone numbers used for alerts.

\section{CONCLUSION}

The design is must have in any enclosed, multi-roomed building with large numbers of people present. In addition, it will also assist current fire materials or security staff in fire prevention and detection. Possible advancements on the design have already been analysed and hold promise such as historical recording of past events using logs and graphs.

\section{REFERENCES}

[1] S. Chen, B. Mulgrew, and P. M. Grant, "A clustering technique for digital communications channel equalization using radial basis function networks," IEEE Trans. on Neural Networks, vol. 4, pp. 570-578, July 1993.

[2] Hochiki, "HCA - Conventional Fire Alarm Control Panel," Internet: [Online]. Available: http://hochiki.specialbrand.net/products.php?option=viewSubcatandcI $\mathrm{D}=2$ andscID=7, [11/10/2011]

[3] Hochiki, "FireNET Plus - Analog Addressable Fire Alarm Control Panel," Internet: [Online]. Available: 
http://hochiki.specialbrand.net/products.php?option=viewSubcatandcI $\mathrm{D}=1$ andscID $=1,[11 / 10 / 2011]$

[4] W. M Croft,, "Fires Involving Explosions - A Literature Review," Fire Safety Journal, vol. 3, pp. 3-24, 1980/81

[5] G. Healey, D. Slater, T. Lin, B. Drda, and A. D. Goedeke, "A system for real-time fire detection," in Proceedings of IEEE Computer Society Conference on Computer Vision and Pattern Recognition, 1993, pp. 18-20, 1 736. pp. 605-606.

[6] Z. G. Liu, J. M. Makar, and A. K. Kim, "Development of fire detection systems in the intelligent building," 12th International Conference on Automatic Fire Detection, Gaithersburg, MD., U.S.A., March 26, 2001, pp. 561-573.
[7] H. Ruser and V. Magori, "Fire detection with a combined ultrasonic-microwave Doppler sensor," in Proceedings of IEEE Ultrasonics Symposium, vol.1, 1998, pp. 489-492.

[8] D. Kohl, J. Kelleter, and H. Petig, "First Detection of Fires by Gas Sensors," published online: 13 JUN 2001 DOI: 10.1002/1616-8984(200105)9:1161:AID SEUP1613.0.CO;2-A

[9] S. Sharples, V. Callaghan, and G. Clarke, "A Multi-Agent Architecture for Intelligent Building Sensing and Control," Sensor Review, vol. 19 no. 2, pp.135-140, 1999.

[10] B. J. Meacham, "International Developments in Fire Sensor Technology" Journal of Fire Protection Engineering, vol. 6, no. 2, 1994, pp 89-98.

[11] W. L. Grosshangler, "1995 Workshop on Fire Detection Research" NISTIR 5700, June 1995. 